\title{
ASSESSMENT OF CORROSION EFFICIENCY AND VOLATILE ORGANIC COMPOUNDS CONTENT FOR A GREEN COATING WITH NOVEL ADDITIVE OF Leucaena leucocephala
}

\author{
WAN MOHAMAD IKHMAL WAN MOHAMAD KAMARUZZAMAN ${ }^{1,2}$, MARIA FAZIRA \\ MOHD FEKERI ${ }^{1,2}$, MUHAMAD SYAIZWADI SHAIFUDIN ${ }^{1}$, NURSABRINA AMIRAH MOHD \\ NASIR $^{1,2}$, MOHD SABRI MOHD GHAZALI*1,2,3 ${ }^{*}$ AND WAN RAFIZAH WAN ABDULLAH ${ }^{2,3,4}$ \\ ${ }^{1}$ Advanced Nano Materials (ANoMa) Research Group, Faculty of Science and Marine Environment, ${ }^{2}$ Materials and \\ Corrosion Research Group, ${ }^{4}$ Faculty of Ocean Engineering Technology and Informatics, Universiti Malaysia Terengganu, \\ 21030 Kuala Nerus, Terengganu, Malaysia. ${ }^{3}$ Materials Synthesis \& Characterization Laboratory (MSCL), Institute of \\ Advanced Technology, Universiti Putra Malaysia, 43400 UPM Serdang, Selangor, Malaysia.
}

*Corresponding author: mohdsabri@umt.edu.my

Submitted final draft: 25 July $2020 \quad$ Accepted: 25 August 2020

http://doi.org/10.46754/jssm.2021.06.004

\begin{abstract}
A large number of anti-corrosion coatings containing volatile solvents with aliphatic hydrocarbons, formaldehyde and benzene are produced annually with the risk of releasing harmful volatile organic compounds (VOCs) into the air. In this study, a commercial coating product for protecting steel is compared with the newly formulated green coating for the quantification of VOC content. The comparison was executed using the mass difference method following ASTM D2369-03. The extract and formulated coating were also subjected to optical, electrochemical and morphological studies, ie, Fourier Transform Infrared (FTIR) Spectroscopy, Ultraviolet-Visible (UV-Vis) Spectroscopy, Electrochemical Impedance Spectroscopy (EIS) and Scanning Electron Microscope/Energy Dispersive $\mathrm{X}$-Ray (SEM/EDX). Based on the extract characterization, functional groups of hydroxyl, carboxylic acid and carbonyl with wavenumbers of $3350 . \mathrm{cm}^{-1}, 2947.23 \mathrm{~cm}^{-1}$ and 1053.13 $\mathrm{cm}^{-1}$, respectively were identified. Also, coating with $3 \mathrm{wt} . \%$ of Leucaena leucocephala leaves extract (LLE), P2 showed a consistent optimum performance in reducing corrosion until the $40^{\text {th }}$ day with a rate of $3.14 \times 10^{-3} \mathrm{~mm} /$ year. The $\mathrm{P} 2$ sample was later subjected to VOCs content analysis, and the outcome displayed a lower VOCs content of $345.40 \mathrm{~g} / \mathrm{L}$ compared to a commercial product, which fulfilled the standard requirement for low-VOC paint by the Environmental Protection Agency (EPA). Hence, it can be concluded that the developed green anticorrosion coating possessed low VOCs content with excellent abilities in protecting steel exposed to an aggressive environment.
\end{abstract}

Keywords: Paint coatings, sustainable coating, marine corrosion, volatile organic compounds, Tafel plot.

Abbreviations: EIS, PP, SS316L.

\section{Introduction}

Corrosion is an unpleasant natural occurrence that results in the deterioration and degradation of most metals. The process involves redox reactions that can be accelerated by two main factors; primary and secondary. The primary factor relates to the characteristics of the metal itself. Generally, some metals corrode faster than others, and a simple way to distinguish the susceptibility of metal toward corrosion is through the value of electrode potential. Metals that have a low electrode potential (eg, magnesium and zinc) are prone to corrosion while metals with a high electrode potential (eg, platinum and gold) possess greater resilience towards it (Dev, 2014; Revie \& Uhlig, 2008). In contrast, the secondary factors are based upon environmental conditions, including temperature, salinity, and contamination. Through changes of these parameters in the environment, metals can either corrode faster or slower (Bordoloi, 2017; Cicek, 2017; George \& Nešic, 2007; Tzaneva, 2013). For the past few decades, corrosion has caused enormous economical loss through maintenance and substitution costs. An exposed metallic structure in a harsh environment, such as seawater with no suitable protective mechanism will not last long. As such, the need for suitable control and prevention methods of corrosion to preserve these structures is critical. 
There are 5 standard methods to control corrosion: inhibitor, cathodic protection, design, material selection and coating. For an open system like the marine environment, the most suitable method is a coating. The coating is a single or multi-component system that protects the steel from the surrounding environment. The elements of the coatings may include organic and inorganic substances. An example of a popular inorganic material in a coating is iron oxide that physically protects the steel through sacrificial action by forming a tight barrier (Benda \& Kalendová, 2017; Deyá et al, 2004; Razavi et $a l, 2018)$. Previously, the use of iron oxide was combined with chromate due to the passivation effect that gives the coating a higher resistance. Unfortunately, because of the strict restrictions on the use of chromate and other similar heavy metals because of high toxicity and carcinogenic properties, researchers are now in pursuit of a better alternative that is eco-friendly (Faisal \& Hasnain, 2006; Novotnik et al, 2012; Ray, 2016; Shabani-Nooshabadi et al, 2014).

Such a coating should have a reduced impact on the environment and low production cost, yet effective. To achieve these desired properties, numerous researchers since decades ago have turned towards natural sources in the hunt for green corrosion inhibitors (Fidrusli \& Mahmood, 2018; Marzorati et al, 2019; Mo et al, 2016; Peter et al, 2015; Shehata et al, 2018; Verma \& Ebenso et al, 2018). To date, a variety of plants tested have verified ability to reduce the rate of corrosion on metals in a corrosive environment (Shabani-Nooshabadi et al, 2015). These organic inhibitors have excellent efficiency in dealing with corrosion due to the presence of heteroatoms within its molecular structures, ie nitrogen, oxygen and sulfur (AlBaghdadi et al, 2018; Lai et al, 2017; Verma, Verma, et al, 2018). In this study, we employ natural materials in a different way. From its common usage as an inhibitor, the material is now deployed as an additive to a coating. The utilization is based on several previous studies which showed that an optimum addition of plant extracts in a coating could increase overall performance by producing tougher barrier properties (Shabani-Nooshabadi et al, 2011; Jafari et al, 2016(a); Jafari et al, 2016(b); ). Hence, the use of Leucaena leucocephala leaf extract (LLE) in a newly formulated coating for this project is expected to give new insights into the working ability of this material. Additionally, the critical motivation on selecting this plant is because of previous studies that found it possessed high antioxidative property compared to the same species in its family (Haggag et al, 2011; Mohammed et al, 2015; Zarina et al, 2017)

Apart from ensuring the capability of the coating, health and safety concerns over exposure to VOCs in the formulated coatings is of utmost importance. VOCs is described as organic compounds that have high vapour pressure and quickly evaporate at room temperature. It is a carbon-based contaminant and poses severe health impacts on humans. The risk of diseases caused by VOCs ranges from short- to long-term adverse effects, depending on the type and period of exposure (Fan et al, 2012; Hong et al, 2017; Khanchi et al, 2015; Shuai et al, 2018; Yu \& Kim, 2012). An example of VOC is the aliphatic amine. It is a compound identifiable by an unpleasant smell with a potential to form carcinogenic nitrosamines in the air after emitted for a certain period. The use of such a coating on a structure for an extended period risks exposing people to the emitting VOC (Censullo et al, 2003; Dinh et al, 2016; Eklund $\&$ Nelson, 1995). Hence, researchers have developed a variety of techniques to measure the amount of VOCs emitted by coatings and established the corresponding standards to decrease the risk of detrimental health effects on humans. In this project, the coating will not only be tested for its efficiency in reducing corrosion, but it will also be subject to the standard VOCs test to ensure that it does not emit compounds beyond the amount allowed bt the authorities. Furthermore, the obtained VOCs result will also be compared with the yields obtained from a similar test conducted on a commercial anticorrosion coating product. 


\section{Materials and Methods}

Surface Preparation of Stainless Steel $316 \mathrm{~L}$ (SS316L)

The substrates were prepared following ASTM E3-11, where each was cut into $25 \mathrm{~mm} \times 25 \mathrm{~mm}$ $\mathrm{x} 3 \mathrm{~mm}$ rectangles. A hole was drilled through each specimen at the top site and polished with emery paper of various grades (240-1000). The samples were soaked in acetone for 5 minutes, rinsed with distilled water, dried using clean tissue, and immediately stored in a dry box before use.

\section{Leucaena leucocephala Extraction (LLE) Process}

The dry powder of Leucaena leucocephala leaves was soaked in $80 \%$ ethanol following the ratio of $1: 10$. About $30 \mathrm{~g}$ of the dry powder was placed into a conical flask with $300 \mathrm{ml}$ of $80 \%$ ethanol and left on a shaker for 24 hours. The mixture was filtered using Whatman no. 1 filter paper and extracted with a rotary evaporator. The residue or crude extract obtained was stored in the refrigerator before the incorporation into the coating as an additive.

\section{Fourier Transform Infrared (FTIR) Spectroscopy}

The Fourier transform infrared (FTIR) spectroscopy was employed to analyze the presence of functional groups in the crude extract. The technique works by firing an infrared beam through the targeted sample and measuring the difference of the output transmittance, which functions as a fingerprint of a functional group. The characterization was performed with a Thermo Nicolet 380 FTIR spectrometer with the frequency range of 400 $\mathrm{cm}^{-1}$ to $4000 \mathrm{~cm}^{-1}$ using the resolution of $4 \mathrm{~cm}^{-1}$.

\section{Ultraviolet-Visible Spectroscopy (UV-Vis)}

The absorbance of LLE was analyzed using ultraviolet-visible spectroscopy (UV-Vis) by operating a Perkin Elmer Lambda 265 UV-Vis spectrometer. The evaluation was conducted within the range of $200-800 \mathrm{~nm}$ with ethanol as the blank.

\section{Formulation of Coating with LLE as the Additive}

The coating was formulated according to Table 1 by employing the WW (Water White) rosin as the binder, methyl isobutyl ketone (MIBK) as the solvent, LLE as the additive, and calcium carbonate $\left(\mathrm{CaCO}_{3}\right)$ and zinc oxide $(\mathrm{ZnO})$ as the pigments. The preparation was executed by mixing the WW rosin and MIBK for 4 hours on a stirrer until no coagulant was present. $\mathrm{CaCO}_{3}$ and $\mathrm{ZnO}$ were then added slowly with continuous stirring to ensure the mixture is well dispersed. Finally, LLE was added and stirred for another 2 hours. The coating was applied to SS316L on only one side using a brush with the thickness of the coating standardized to $120 \pm 10 \mu \mathrm{m}$ (Mostafaei \& Nasirpouri, 2014). The specimens were left in an oven at $52^{\circ} \mathrm{C}$ overnight. Samples were later stored in a dry box before proceeding to the next procedures.

Table 1: Coating Formulation by weight $\%$

\begin{tabular}{cccccc}
\hline Component/Paint & P1 & P2 & P3 & P4 & P5 \\
\hline WW Rosin & & 49.1 & & \\
MIBK & & 20.0 & & \\
$\mathrm{CaCO}_{3}$ & 20.0 & 17.0 & 10.9 & & 8.0 \\
$\mathrm{ZnO}$ & 0 & 3 & 6 & 11.0 & 12 \\
Extract & & & & 9 & \\
\hline
\end{tabular}




\section{VOCs Content Analysis}

The investigation on the VOC content was conducted on the formulated coating with the best overall performance, ie P2, and the commercial anti-corrosion coating. The formulation was improvised to match the requirement set up by ASTM D2369-03 where the precondition is to use only $3 \mathrm{~mL}$ of solvent. Aluminium foil was moulded into a dish $58 \mathrm{~mm}$ in diameter and $18 \mathrm{~mm}$ hight. The aluminium foil dish was weighed $\left(\mathrm{W}_{1}\right)$ with an analytical balance and then pretreated in an oven at 110 $\pm 5^{\circ} \mathrm{C}$ for 30 minutes. About $3 \mathrm{ml}$ of solvent was placed into the aluminium dish with the corresponding coating mixture added slowly. The mixture was stirred gently using a paper clip. The weight of the aluminium dish with coating was next measured $\left(\mathrm{W}_{2}\right)$. The sample was then placed inside an oven for 60 minutes at $110 \pm 5^{\circ} \mathrm{C}$ with its duplicate. After 60 minutes, samples were taken out to measure weight loss $\left(\mathrm{W}_{3}\right)$. Calculation of the weight of volatile components, $\mathrm{W}_{\mathrm{v}}$ was executed using Equation 1 where $\mathrm{W}_{1}$ is the weight of aluminium dish with coating before heating, $\mathrm{W}_{2}$ is is the weight of aluminium dish with coating after heat and $\mathrm{W}_{3}$ is the weight of the coating. The weight fraction of solids, $\mathrm{W}_{\mathrm{s}}$ was later calculated using Equation 2.

$$
\begin{gathered}
W_{v}=\frac{W_{1}-W_{2}}{W_{3}} \\
W_{s}=1-W_{v}
\end{gathered}
$$

Equation 1

Equation 2

\section{Immersion Test}

The immersion of coated and uncoated SS316L was performed using artificial seawater formulated using ASTM D1141-98(2013) inside a laboratory. A specific amount of artificial seawater calculated in accordance with ASTM G31-72 was filled into a container. The specimens were hung inside the container using a string that passes through a drilled hole and tied to the casing. Samples were collected every 10 days for corrosion analysis of EIS, PP, and SEM/EDX.

\section{Electrochemical Impedance Spectroscopy (EIS)}

EIS was employed to examine the impedance and capacitance of the coated and uncoated SS316L when exposed to the aggressive solution for an extended period. The experimental setup used alternating current (AC) with an Autolab PGSTAT302N to measure the changes which occurred on the surface of substrates. The evaluation was performed within the frequency range of $10 \mathrm{kHz}$ to $0.01 \mathrm{~Hz}$. Data obtained were analyzed and fit using NOVA 1.10 program, where the corresponding Nyquist plot of each specimen was tabulated.

\section{Potentiodynamic Polarization (PP)}

PP (Potentiodynamic polarization) is a common technique to measure the corrosion resistance, where it provides a general evaluation of the inhibitive mechanism of the targeted sample. A conventional three-electrode cell - a counter electrode (CE), reference electrode (RE) and working electrode (WE) - were used in the analysis. The measurement recorded the changes in the potentiodynamic current potential curves from $-1.0 \mathrm{~V}$ to $0.3 \mathrm{~V}$ with a scanning rate of 10 $\mathrm{mVs}^{-1}$. Data obtained were analyzed and fit using NOVA 1.10 program where the corresponding Tafel plot of each specimen was tabulated.

\section{Scanning Electron Microscope/Energy Dispersive X-Ray (SEM/EDX)}

SEM/EDX was performed to study the morphology and the distribution of elements on the surface of coated samples. Through this inspection, the degree of degradation can be directly determined and compared with the data obtained from EIS and PP. Additionally, the distribution of elements gives an insight into the formation of salt deposition and leaking of corrosion products on the surface of the substrate. The evaluation was executed using an SEM model of JEOL JSM-6360LA coupled to an energy dispersive $\mathrm{x}$-ray. Setup parameters were $15 \mathrm{kV}$ accelerated voltage at the magnification of $\mathrm{x} 100$. 


\section{Results and Discussion}

\section{Fourier Transform Infrared (FTIR) Spectroscopy}

The pFTIR study on the leaf extracts of Leucaena leucocephala yields for the identification of multiple functional groups, as displayed in Figure 1 with the corresponding tabulated data in Table 2. From Figure 1, a peak was determined at $3350.35 \mathrm{~cm}^{-1}$, which correlates to the $\mathrm{O}-\mathrm{H}$ functional group with strong and broad characteristics . Similar groups were also identified at $2947.23 \mathrm{~cm}^{-1}$ and 1053.13 $\mathrm{cm}^{-1}$, where both represent carboxylic acid and carbonyl, respectively. Additionally, the groups of amide $\left(1642.42 \mathrm{~cm}^{-1}\right)$ and alkyl (2891.29 $\mathrm{cm}^{-1}$ ) were also detected, with the appearance of strong and weak peaks, respectively. These several identifications are in agreement with the finding of previous works which correlate the results to the structure of major compounds in LLE, such as quercetin and gallic acid (Zayed \& Samling, 2016).

\section{Ultraviolet-visible Spectroscopy (UV-Vis)}

The absorbance characterization was executed using UV-Vis in the radiation regions of visible and ultraviolet, between 200 and $800 \mathrm{~nm}$. Figure 2 shows the UV-Vis spectrum of LLE. An absorption band was identified at $276 \mathrm{~nm}$, possibly yielding for the transition of $n$. The result was compared to the standard UV-Vis absorbance list, where it was in agreement with the functional groups of cinnamic acid $(\mathrm{C}=\mathrm{O}$ and $\mathrm{R}-\mathrm{OH}$ ). Furthermore, an additional peak was also spotted at $665 \mathrm{~nm}$ which was included in the visible region responsible for the color of the substance. The peak at $665 \mathrm{~nm}$ correlates to the colour green.

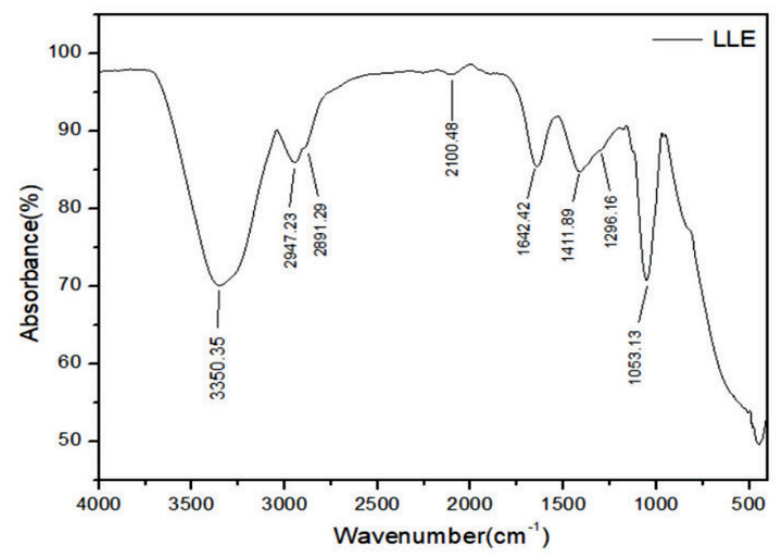

Figure 1: FTIR spectrum of LLE

Table 2: Peaks characteristic of LLE

\begin{tabular}{cccc}
\hline $\begin{array}{c}\text { Wavenumber } \\
\left(\mathbf{c m}^{-1)}\right.\end{array}$ & Bond & Functional Group & Appearance \\
\hline 3350.35 & O-H stretch & Alcohol & Strong and broad \\
2947.23 & O-H stretch & Carboxylic acid & Strong \\
2891.29 & $\mathrm{C}-\mathrm{H}$ stretch & Alkyl & Weak \\
2100.48 & $\mathrm{C} \equiv \mathrm{C}$ stretch & Alkynes & Weak \\
1642.42 & $\mathrm{C}=\mathrm{O}$ stretch & Amide & Strong \\
1411.89 & $\mathrm{NO}_{2}$ stretch & Nitro & Strong \\
1296.16 & $\mathrm{C}-\mathrm{O}$ stretch & Ester & Medium \\
1053.13 & $\mathrm{C}-\mathrm{OH}$ stretch & Carbonyl & Strong \\
\hline
\end{tabular}




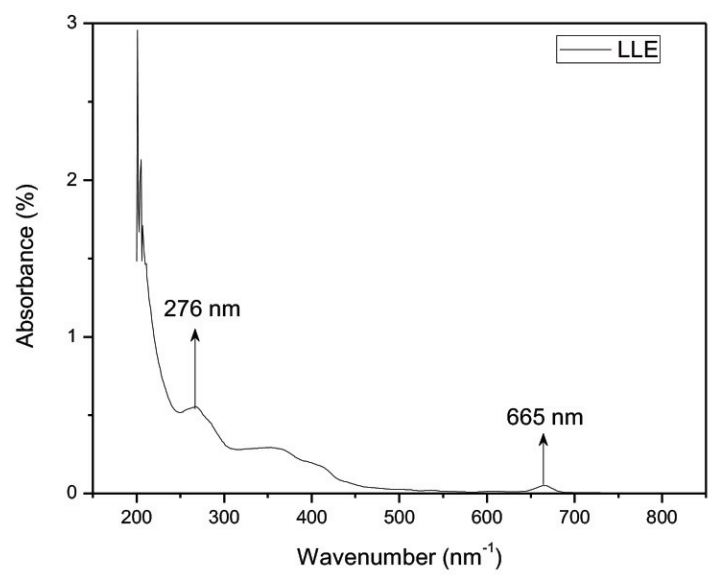

Figure 2: Absorbance spectrum of LLE

\section{VOCs Content Evaluation}

The formulated coating with the best performance based on electrochemical and morphological studies was compared with the commercial anti-corrosion coating for VOCs content evaluation using the method described in ASTM D2369-03. All samples were replicated, and the average results were tabulated in Table 3. The data demonstrates a slight difference between coatings, where the formulated coating possessed a lower percentage of volatile components than the commercial coating. Fortunately, in accordance with the standard set by the US EPA for oil-based paint, coatings with VOC content below $380 \mathrm{~g} / \mathrm{L}$ can be considered as a low VOC paint and safe to be used. However, most reputable suppliers of coatings nowadays tend to decrease the VOCs content even further as a means to promote the product and increase safety. Hence, further research needs to be conducted to follow up on this trend while still ensuring the high efficiency of the product.

\section{Electrochemical Impedance Spectroscopy (EIS)}

The performance of coatings in acting as the barrier that protects the SS316L from aggressive electrolytes was examined using EIS. The impedance study is a common practice, where it directly measures the changes in the electrochemical parameters. In this study, a standard equivalent circuit with the time constant of a resistor and capacitor was employed to mimic the phenomenon. Data obtained from the measurements were tabulated in Table 4 with the corresponding Nyquist plots shown in Figure 3. Based on the shape of the semicircle obtained in Figure 3, most of the samples exhibited the same mechanism where the changes are primarily affected by the charge transfer resistance. It means that the working principle of the coating is like a sturdy barrier where it prevents the electrolytes from entering and comes into contact with the steel. This prevention ensures that no formation of ionic current path occurs; thus, no substance will be reduced at the cathode, and the corrosion process is stopped. There are two main measurements tabulated in

Table 3: Comparison of total weight fraction and density for the formulated and commercial coatings

\begin{tabular}{ccccc}
\hline Coating & \multicolumn{3}{c}{ Total Weight Fraction \& Density (g/L) } \\
\cline { 2 - 5 } & \multicolumn{3}{c}{ Volatile } & \multicolumn{2}{c}{ Non-volatile } \\
\hline P2 (3 wt.\% LLE) & 0.31 & 345.40 & 0.69 & 377.85 \\
\hline Commercialized Coating & 0.33 & 754.60 & 0.67 & 767.15 \\
\hline
\end{tabular}


Table 4, ie, charge transfer resistance, $R_{c t}$, and double layer capacitance, $C_{d l}$. The $R_{c t}$ denotes the susceptibility of the formation of corrosion product at the interface of the coating and the substrate. It directly measures the value of resistance to charge transfer between the anode and cathode on the surface, and deduced it on the semicircle of the Nyquist plot. As the value of $R_{c t}$ increases, the size of the semicircle will increase, and hence, the rate of corrosion will decrease. In contrast, the $C_{d l}$ quantifies the amount of water or electrolytes, which has been absorbed by the coating. The coating generally has a lower amount of electrical permittivity $(2$ $\mathrm{Fm}^{-1}$ to $\left.7 \mathrm{Fm}^{-1}\right)$ as compared to water $\left(\sim 80 \mathrm{Fm}^{-}\right.$ $\left.{ }^{1}\right)$. Hence, as the water begins to absorb into the coating matrix, the electrical permittivity will start to increase and thus raising the capacitance value. As such, when capacitance increases, the degradation and formation of the delaminated area under the coating also increases.

During the 10 days of immersion, P2 with 3 wt.\% of LLE has the highest $R_{c t}$ of $7.02 \times 10^{3}$ $\Omega . \mathrm{cm}^{2}$ and followed by P3 with 6 wt.\% of LLE, at $4.77 \times 10^{3} \Omega . \mathrm{cm}^{2}$. The trend remains the same after 40 days of immersion with P2 in the leads. However, a fluctuation was observed at 30 days of immersion, where P3 took the lead while P2 was the second highest. During the last 50 and 60 days of immersion, the overall performance of coatings displayed a significant drop in both parameters. This is because of the increased penetration of aggressive electrolytes into the coatings matrix. Even though an exceptionally large reading in $R_{c t}$ was observed for P5 with $12 \mathrm{wt} \%$ of LLE during this period, the phenomenon is only due to the occurrence of excessive degradation causing it to partially peel off. This state later yields the formation of complexes between the oxide layer and the remaining coating to produce such an outcome. As for the measurement of $C_{d}$, similar readings with slight differences were displayed by most coatings during the first 20 days of immersion. A significant fluctuation was however observed during the $30^{\text {th }}$ day of immersion, which might be attributed to the sacrificial reaction of $\mathrm{ZnO}$ within the coatings. At 40 and 50 days of immersion, the readings began to stabilize, with the majority of coatings showing comparable values. After 60 days of immersion, $\mathrm{P} 2$ exhibited the lowest $C_{d l}$ compared to other coatings and since the morphological observation showed that P2 has an intact and strong structure after the period, it proves that the stability of $\mathrm{P} 2$ was the optimum. Furthermore, based on the distribution of elements assessment, the detection of chromium and nickel (two major components of SS316L) were at a deficient level, which indicates the intact structure of $\mathrm{P} 2$ in protecting the substrate.

\section{Potentiodynamic Polarization Measurement}

The characterization of potentiodynamic polarization provides an insight into the anodic and cathodic mechanism on the substrates. The evaluation is represented from several parameters such as corrosion potential $\left(E_{\text {corr }}\right)$, corrosion current density $\left(i_{\text {corr }}\right)$, and corrosion rate $(C R)$. Through the provided data, the inhibitive action, either anodic, cathodic or mixed can be determined. Table 5 shows the data acquired from the analysis with the corresponding Tafel plots for each coated and uncoated substrate for 60 days, as represented in Figure 4. Through Figure 4(a), for coatings after 10 days of immersion, the application of coating results in a shift of Ecorr towards a more positive value in comparison to the uncoated SS316L. Additionally, the coating with the best performance was displayed by P2 with 3 wt.\% of LLE, where its measured parameters were $E_{\text {corr }}=0.5905 \mathrm{~V}, i_{\text {corr }}=9.92 \times 10^{-7}{\mathrm{~A} . \mathrm{cm}^{2}}^{2}$, and $C R=1.66 \times 10^{-3} \mathrm{~mm} /$ year. The shift indicates the increased electro-positivity of the coated substrates, implying higher resistance towards corrosion. Furthermore, a significant drop in the icorr can be attributed to the lesser amount of corrosive agents that can penetrate the coating matrix.

A similar trend was observed at the 30 days of the immersion test, where $\mathrm{P} 2$ retained its higher efficiency compared to other coatings. The decrease in the performance of other coatings is because of the high penetration of electrolytes into the coatings matrix resulting in 
Table 4: Impedance parameters

\begin{tabular}{|c|c|c|c|}
\hline Immersion days & $\begin{array}{l}\text { wt.\% of LLE in } \\
\text { coating }\end{array}$ & $\begin{array}{c}\text { Charge transfer } \\
\text { resistance, } R_{c t}\left(\Omega . \mathrm{cm}^{2}\right)\end{array}$ & $\begin{array}{c}\text { Double layer capacitance, } \\
C_{d l}(\mathrm{~F})\end{array}$ \\
\hline \multirow{6}{*}{10} & Bare & $0.49 \times 10^{3}$ & $0.27 \times 10^{-6}$ \\
\hline & 0 & $2.73 \times 10^{3}$ & $0.97 \times 10^{-6}$ \\
\hline & 3 & $7.02 \times 10^{3}$ & $66.10 \times 10^{-12}$ \\
\hline & 6 & $4.77 \times 10^{3}$ & $40.60 \times 10^{-12}$ \\
\hline & 9 & $3.93 \times 10^{3}$ & $1.92 \times 10^{-6}$ \\
\hline & 12 & $1.78 \times 10^{3}$ & $15.70 \times 10^{-6}$ \\
\hline \multirow{6}{*}{20} & Bare & $13.50 \times 10^{3}$ & $55.50 \times 10^{-6}$ \\
\hline & 0 & $7.21 \times 10^{3}$ & $14.40 \times 10^{-6}$ \\
\hline & 3 & $36.70 \times 10^{3}$ & $1.16 \times 10^{-6}$ \\
\hline & 6 & $8.02 \times 10^{3}$ & $0.42 \times 10^{-6}$ \\
\hline & 9 & $13.90 \times 10^{3}$ & $0.25 \times 10^{-6}$ \\
\hline & 12 & $18.00 \times 10^{3}$ & $0.54 \times 10^{-6}$ \\
\hline \multirow{6}{*}{30} & Bare & $11.80 \times 10^{3}$ & $73.20 \times 10^{-6}$ \\
\hline & 0 & $4.04 \times 10^{3}$ & $1.62 \times 10^{-9}$ \\
\hline & 3 & $39.20 \times 10^{3}$ & $37.30 \times 10^{-9}$ \\
\hline & 6 & $58.10 \times 10^{3}$ & $948.00 \times 10^{-9}$ \\
\hline & 9 & $3.90 \times 10^{3}$ & $970.00 \times 10^{-9}$ \\
\hline & 12 & $2.41 \times 10^{3}$ & $264.00 \times 10^{-9}$ \\
\hline \multirow{6}{*}{40} & Bare & $21.00 \times 10^{3}$ & $17.00 \times 10^{-6}$ \\
\hline & 0 & $14.90 \times 10^{3}$ & $2.06 \times 10^{-6}$ \\
\hline & 3 & $18.20 \times 10^{3}$ & $3.42 \times 10^{-6}$ \\
\hline & 6 & $0.47 \times 10^{3}$ & $0.72 \times 10^{-6}$ \\
\hline & 9 & $5.68 \times 10^{3}$ & $2.46 \times 10^{-6}$ \\
\hline & 12 & $9.58 \times 10^{3}$ & $10.10 \times 10^{-6}$ \\
\hline \multirow{6}{*}{50} & Bare & $14.10 \times 10^{3}$ & $0.64 \times 10^{-6}$ \\
\hline & 0 & $2.00 \times 10^{3}$ & $2.00 \times 10^{-6}$ \\
\hline & 3 & $8.17 \times 10^{3}$ & $0.40 \times 10^{-6}$ \\
\hline & 6 & $1.40 \times 10^{3}$ & $3.06 \times 10^{-6}$ \\
\hline & 9 & $5.93 \times 10^{3}$ & $0.20 \times 10^{-6}$ \\
\hline & 12 & $155.00 \times 10^{3}$ & $0.14 \times 10^{-6}$ \\
\hline \multirow{6}{*}{60} & Bare & $21.70 \times 10^{3}$ & $19.40 \times 10^{-6}$ \\
\hline & 0 & $4.65 \times 10^{3}$ & $0.85 \times 10^{-6}$ \\
\hline & 3 & $5.25 \times 10^{3}$ & $91.80 \times 10^{-9}$ \\
\hline & 6 & $15.7 \times 10^{3}$ & $0.83 \times 10^{-7}$ \\
\hline & 9 & $2.06 \times 10^{3}$ & $0.22 \times 10^{-6}$ \\
\hline & 12 & $29.10 \times 10^{3}$ & $0.67 \times 10^{-6}$ \\
\hline
\end{tabular}



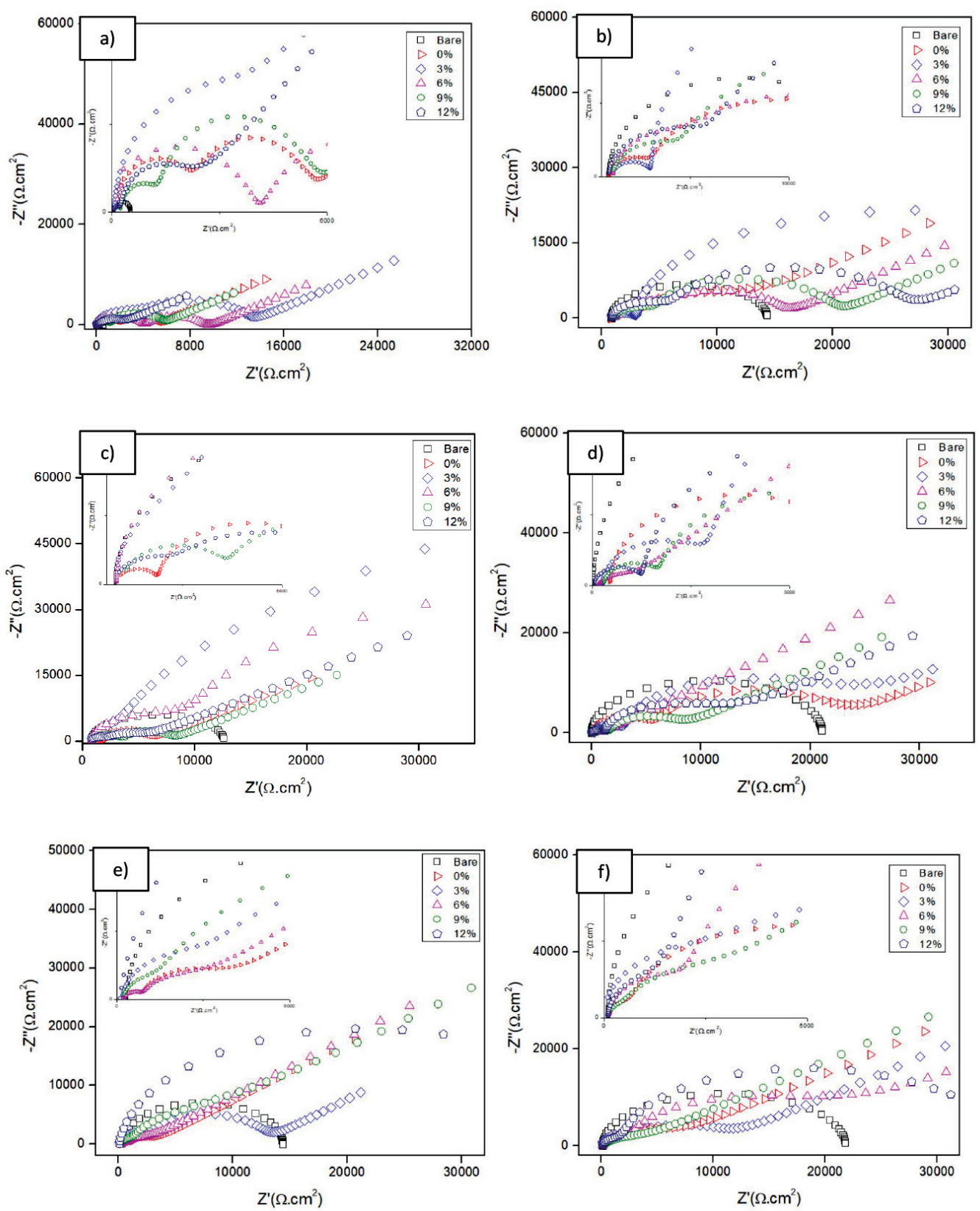

Figure 3: Nyquist plot for coated and uncoated samples at a) 10 day, b) 20 days, c) 30 days, d) 40 days, e) 50 days and f) 60 days 
its degradation. The degradation will produce more percolation networks inside and under the layer of coating, where it will break it down slowly. Interestingly, the uncoated steel samples showed a huge change in its resilience towards corrosion as time passes. The steel are observed to have a huge increase in its performance beyond 10 days as tabulated in Table 5, where it has a significant decrease in both $i_{\text {corr }}$ and $C R$. The phenomenon is due to the formation of the chromium oxide layer on its surface, which acts as a shield for the steel. Although some might dispute the need for a coating on stainless steel since it already has a means to protect itself, the reality is that exposed chromium oxide layer brings detrimental effects to the environment. When a large accumulation of chromium in seawater occurs, it will inevitably be consumed by aquatic life such as fish. This will result in the accumulation of the substance in the gills of fish, causing a lethal effect to its life. In fact, if humans were to consume a large amount of chromium, it will cause various diseases such as severe skin rash. Hence, the need for coating onto the surface of stainless steel is essential. A critical decrease in the value of $i_{\text {corr }}$ indicates that the coatings act as a mixed type corrosion inhibitor, where its inhibitive mechanism involves anodic and cathodic regions. The changes of $E_{\text {corr }}$ moreover indicate which regions of the surface substrate where the coating is more dominant. If the $E_{\text {corr }}$ shifts towards positive value, then it's dominant towards anodic inhibitive action and vice versa for the cathodic inhibitive action. Overall, P2 remained the best coating throughout the immersion period by the evaluation of $i_{\text {corr }}$ and $C R$ (20 days, $i_{\text {corr }}=1.44 \times 10^{-6}$ A.cm $\mathrm{cm}^{2} \& C R=2.39$ $\mathrm{x} 10^{-3} \mathrm{~mm} /$ year; 30 days, $i_{\text {corr }}=1.16 \times 10^{-6} \mathrm{~A} . \mathrm{cm}^{2}$ $\& C R=1.95 \times 10^{-3} \mathrm{~mm} /$ year; 40 days, $i_{\text {corr }}=1.88$ $\mathrm{x} 10^{-6} \mathrm{~A} . \mathrm{cm}^{2} \& C R=3.14 \times 10^{-3} \mathrm{~mm} /$ year; 50 days, $i_{\text {corr }}=6.91 \times 10^{-7} \mathrm{~A} . \mathrm{cm}^{2} \& C R=1.16 \times 10^{-3}$ $\mathrm{mm} /$ year; 60 days, $i_{\text {corr }}=1.92 \times 10^{-6} \mathrm{~A} . \mathrm{cm}^{2} \& C R=$ $3.21 \times 10^{-3} \mathrm{~mm} /$ year). Hence, it can be concluded that the incorporation of $3 \mathrm{wt} . \%$ of LLE provides the optimum enhancement for the anti-corrosion coating of this formulation.

\section{Scanning Electron Microscope/Energy Dispersive X-Ray (SEM/EDX)}

The morphological and elements distribution studies were conducted using SEM/EDX for the coated stainless steel after 60 days of immersion in artificial seawater. The micrographs were displayed in Figure 5 with the data on elements distribution summarized in Table 6. Based on the results, P5, with the highest amount of LLE incorporation, exhibited the worst degradation, which is due to the excessive amount of LLE causing dissociation and lower adherence of the coating structure. A similar observation was also made for P3 with $6 \mathrm{wt} . \%$ of LLE, where the coating surface for both samples has a lot of holes or pores at various places. Additionally, the surfaces of P3 and P5 were also rougher as compared to the other coatings. These conditions are an indication of severe degradation of the coating structures and its low capabilities in dealing with an aggressive solution. On the other hand, P1 with no incorporation of LLE yields the better result as compared to P3, P4, and P5, where its surface is much more smooth. However, the presence of multiple pores with a diameter of $10 \mu \mathrm{m}-50 \mu \mathrm{m}$ were discernible. The condition of P1 can be attributed to the large amount of $\mathrm{ZnO}$ in the formulation, which stabilized the structure from producing any major cracks. However, from the formation of pores, it is evident that the large quantity of $\mathrm{ZnO}$ does not provide a strong repelling action for the coating against corrosive agents.

In summary, the best performance of the formulated coating was in agreement with the previous analysis, where P2 with 3 wt.\% of LLE has a smooth surface with no apparent cracks. Unfortunately, even for P2, the presence of tiny cracks with a diameter of less than 10 $\mu \mathrm{m}$ was still observable. These tiny cracks, if left without any additional action, will later proliferate and become large pores or combine to form large cracks on the coating structure. Also, a few white flakes can be spotted on the surface of P2, which could be salt deposition. As for the analysis of elements distribution, from Table 6, large compositions of the surface were 
Table 5: Potentiodynamic polarization parameters

\begin{tabular}{|c|c|c|c|c|}
\hline Immersion days & $\begin{array}{l}\text { wt.\% of LLE in } \\
\text { coating }\end{array}$ & $\begin{array}{c}\text { Corrosion } \\
\text { potential, } E_{c o r r}(\mathrm{~V})\end{array}$ & $\begin{array}{c}\text { Corrosion current } \\
\text { density, } i_{\text {corr }} \\
(\mathbf{A . c m})^{2} \\
\end{array}$ & $\begin{array}{l}\text { Corrosion rate, } \\
\text { CR (mm/year) }\end{array}$ \\
\hline \multirow{6}{*}{10} & Bare & -0.53002 & $5.29 \mathrm{E}-04$ & 0.88 \\
\hline & 0 & -0.39895 & $2.00 \mathrm{E}-05$ & $3.35 \times 10^{-2}$ \\
\hline & 3 & -0.50905 & $9.92 \mathrm{E}-07$ & $1.66 \times 10^{-3}$ \\
\hline & 6 & -0.52763 & $3.10 \mathrm{E}-06$ & $5.19 \times 10^{-3}$ \\
\hline & 9 & -0.43665 & $1.56 \mathrm{E}-05$ & $2.61 \times 10^{-2}$ \\
\hline & 12 & -0.43270 & $4.06 \mathrm{E}-05$ & 0.06 \\
\hline \multirow{6}{*}{20} & Bare & -0.32795 & $8.68 \mathrm{E}-05$ & 0.15 \\
\hline & 0 & -0.47395 & 7.93E-06 & $1.33 \times 10^{-2}$ \\
\hline & 3 & -0.34252 & $1.44 \mathrm{E}-06$ & $2.39 \times 10^{-3}$ \\
\hline & 6 & -0.52315 & $6.27 \mathrm{E}-06$ & $1.05 \times 10^{-2}$ \\
\hline & 9 & -0.39177 & $5.48 \mathrm{E}-06$ & $9.16 \times 10^{-3}$ \\
\hline & 12 & -0.50751 & 4.24E-06 & $7.09 \times 10^{-3}$ \\
\hline \multirow{6}{*}{30} & Bare & -0.36713 & $10.8 \mathrm{E}-05$ & 0.18 \\
\hline & 0 & -0.41085 & $5.86 \mathrm{E}-06$ & $9.79 \times 10^{-3}$ \\
\hline & 3 & -0.47633 & $1.16 \mathrm{E}-06$ & $1.95 \times 10^{-3}$ \\
\hline & 6 & -0.38963 & $1.05 \mathrm{E}-06$ & $1.75 \times 10^{-3}$ \\
\hline & 9 & -0.35273 & $1.95 \mathrm{E}-05$ & $3.26 \times 10^{-2}$ \\
\hline & 12 & -0.36782 & $2.71 \mathrm{E}-05$ & $4.53 \times 10^{-2}$ \\
\hline \multirow{6}{*}{40} & Bare & -0.41035 & $1.64 \mathrm{E}-05$ & $2.74 \times 10^{-2}$ \\
\hline & 0 & -0.38695 & $3.82 \mathrm{E}-06$ & $6.38 \times 10^{-3}$ \\
\hline & 3 & -0.46967 & $1.88 \mathrm{E}-06$ & $3.14 \times 10^{-3}$ \\
\hline & 6 & -0.43507 & 4.66E-05 & $7.78 \times 10^{-2}$ \\
\hline & 9 & -0.38702 & $2.90 \mathrm{E}-05$ & $4.84 \times 10^{-2}$ \\
\hline & 12 & -0.38460 & $1.23 \mathrm{E}-05$ & $2.05 \times 10^{-2}$ \\
\hline \multirow{6}{*}{50} & Bare & -0.54291 & $1.39 \mathrm{E}-06$ & $2.32 \times 10^{-3}$ \\
\hline & 0 & -0.40142 & $2.31 \mathrm{E}-05$ & $3.91 \times 10^{-2}$ \\
\hline & 3 & -0.4091 & $6.91 \mathrm{E}-07$ & $1.16 \times 10^{-3}$ \\
\hline & 6 & -0.55401 & $6.75 \mathrm{E}-05$ & 0.11 \\
\hline & 9 & -0.42867 & $3.20 \mathrm{E}-06$ & $5.35 \times 10^{-3}$ \\
\hline & 12 & -0.35599 & $6.49 \mathrm{E}-08$ & $1.08 \times 10^{-4}$ \\
\hline \multirow{6}{*}{60} & Bare & -0.40565 & $3.44 \mathrm{E}-06$ & $5.74 \times 10^{-3}$ \\
\hline & 0 & -0.47897 & 7.02E-06 & $1.17 \times 10^{-2}$ \\
\hline & 3 & -0.34264 & $1.92 \mathrm{E}-06$ & $3.21 \times 10^{-3}$ \\
\hline & 6 & -0.31727 & $1.09 \mathrm{E}-06$ & $1.82 \times 10^{-3}$ \\
\hline & 9 & -0.43476 & $1.35 \mathrm{E}-05$ & $2.26 \times 10^{-2}$ \\
\hline & 12 & -0.31113 & $1.56 \mathrm{E}-06$ & $2.61 \times 10^{-3}$ \\
\hline
\end{tabular}



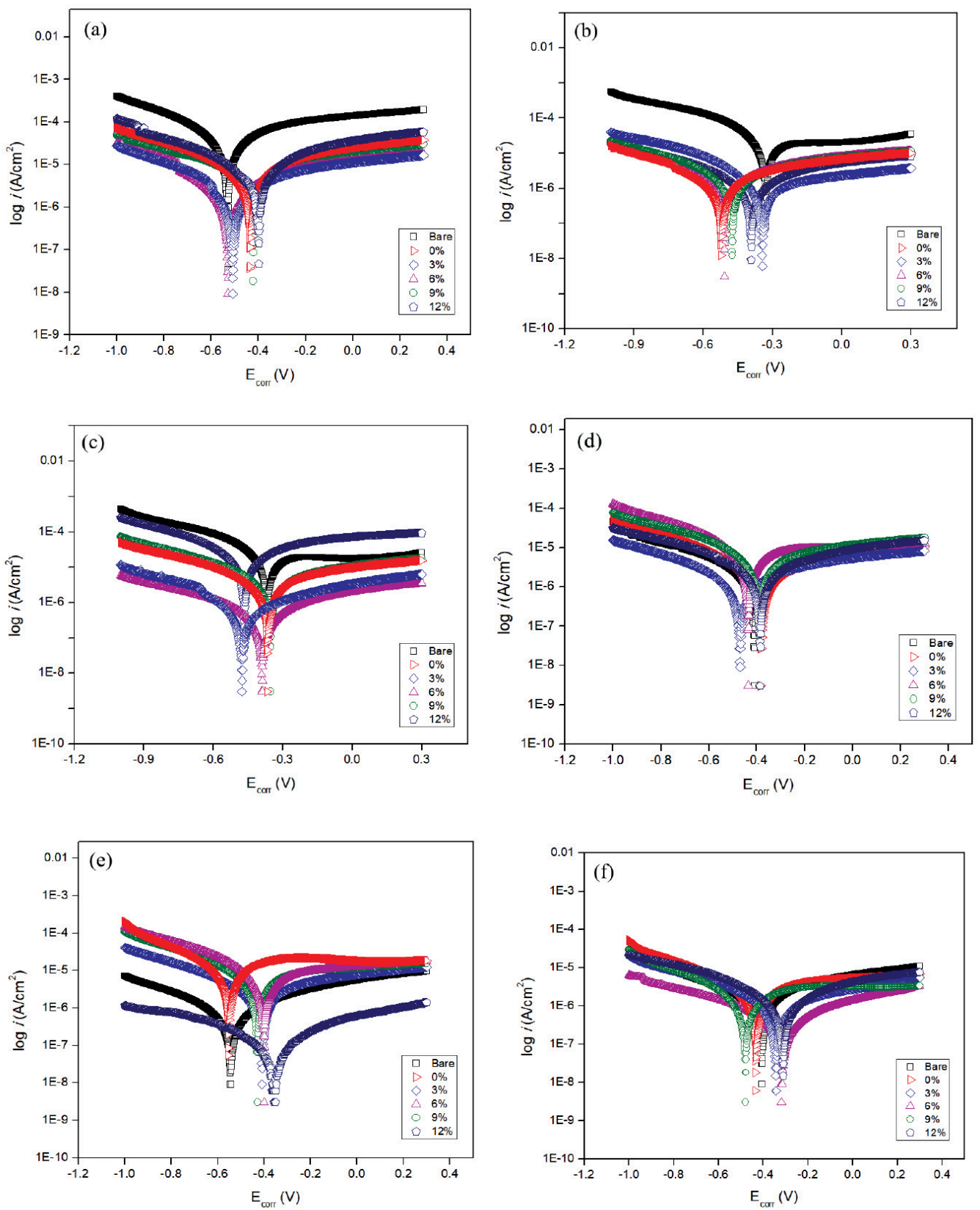

Figure 4: Tafel plot for coated and uncoated samples at a) 10 days, b) 20 days, c) 30 days, d) 40 days, e) 50 days and f) 60 days

filled with sodium $(\mathrm{Na})$ and chloride $(\mathrm{Cl})$, which were the main components of salt. Furthermore, small percentages of $\mathrm{Cr}$ and $\mathrm{Ni}$ were also detected, possibly due to the accumulation of the elements in the solution from the uncoated surfaces of SS316L. In closing, more studies on the formulation, selection and optimization of the coatings are required to increase its protective abilities for a future project. 
Table 6: Percentage of elements distribution on P2 surface after 60 days of immersion in artificial seawater

\begin{tabular}{ccc}
\hline Element & $\mathbf{( k e V )}$ & Mass (\%) \\
\hline Sodium $(\mathrm{Na})$ & 1.041 & 64.12 \\
Chloride $(\mathrm{Cl})$ & 2.621 & 21.74 \\
Chromium $(\mathrm{Cr})$ & 5.411 & 1.88 \\
Nickel $(\mathrm{Ni})$ & 7.471 & 12.26 \\
\hline Total & & 100 \\
\hline
\end{tabular}
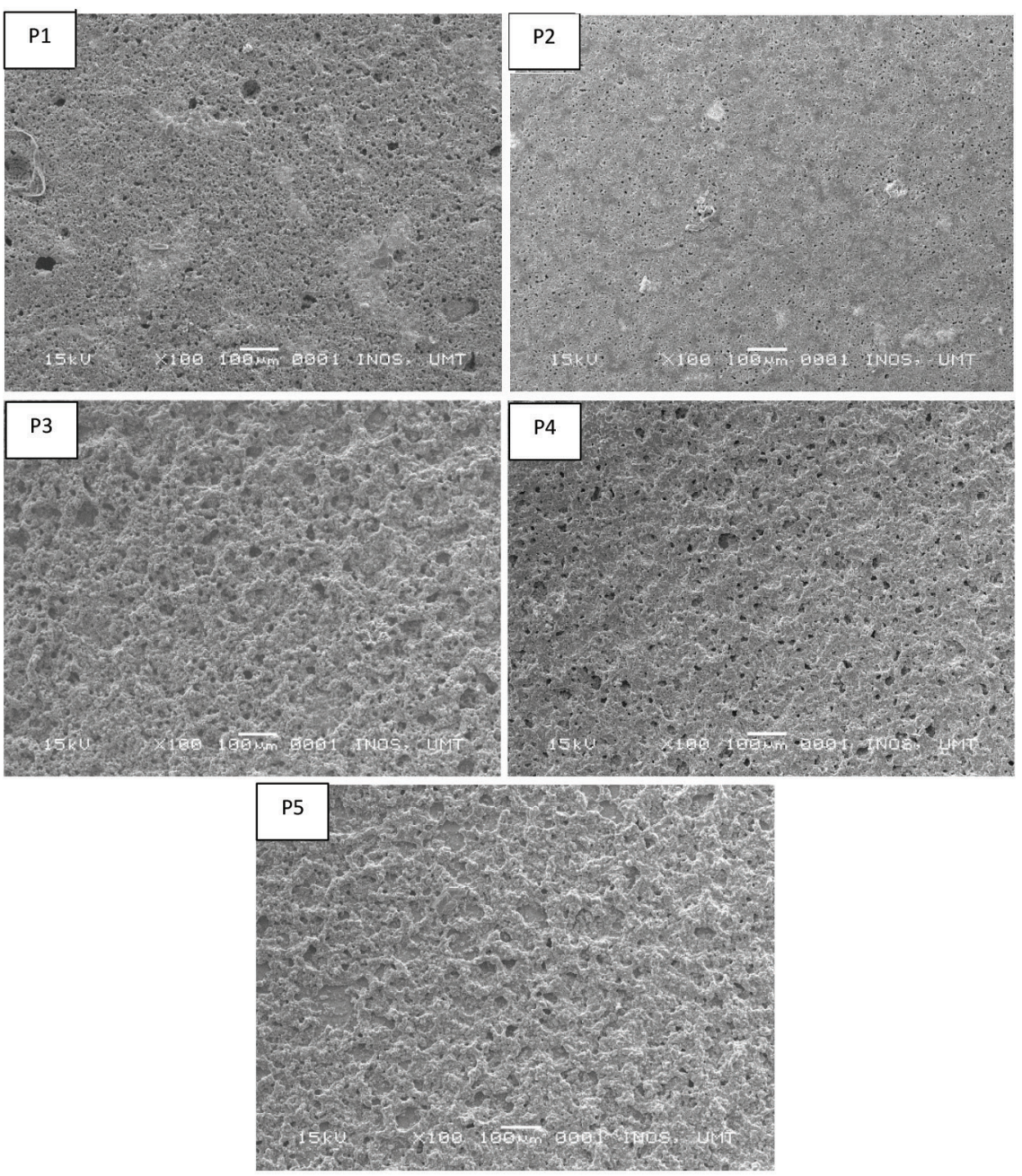

Figure 5: SEM images of samples after 60 days of immersion test 


\section{Conclusion}

The leaf extract of Leucaena leucocephala as an additive for a formulated green coating has been successfully produced and analyzed. Optical studies via FTIR and UV-Vis give insight towards the possible structure of compounds within the extract, which boosted its high antioxidant property. Some major functional groups, such as alcohol and carboxylic acid, that possess heteroatoms are believed to be responsible for providing the coating with an enhanced structure. The measurement of VOCs content also yields a positive outcome where the formulated coating with the optimum performance, $\mathrm{P} 2$. can be categorically included as a low VOC paint based on the regulation authorized by the EPA. As for the corrosion efficiency characterization using EIS, PP and SEM/EDX, the formulated coating of P2 with 3 wt.\% of LLE outperformed other coatings, showing the best resilience towards corrosion either through $t$ electrochemical measurement of morphological observation.

\section{Acknowledgments}

The authors would like to express their highest gratitude to the Ministry of Higher Education Malaysia for funding this research project under Fundamental Research Grant Scheme (Vot no. 59537).

\section{References}

Al-Baghdadi, S. B., Hashim, F. G., Salam, A. Q., Abed, T. K., Gaaz, T. S., Al-Amiery, A. A., Kadhum, A. A. H., Reda, K. S., \& Ahmed, W. K. (2018). Synthesis and corrosion inhibition application of NATN on mild steel surface in acidic media complemented with DFT studies. Results in Physics, 8, 1178-1184.

Benda, P., \& Kalendová,A. (2017). Development and preparation of oxide mixture-based pigments for anticorrosion paints. Pigment \& Resin Technology, 46(5), 342-355.
Bordoloi, I. (2017). Inhibition of Carbon Steel Corrosion in Closed-loop-water Heating/ cooling Systems Using Sodium Caprylate as an Environmentally-friendly Corrosion Inhibitor [Master Thesis. McGill University Libraries, Montreal, CA].

Censullo, A. C., Jones, D. R., \& Wills, M. T. (2003). Speciation of the Volatile Organic Compounds (VOCs) in solventborne aerosol coatings by solid phase microextractiongas chromatography. Journal of Coatings Technology, 75(936), 47-53.

Cicek, V. (2017). Corrosion engineering and Cathodic protection handbook: With extensive question and answer section. Massachusetts, USA: John Wiley \& Sons.

Dev, S. (2014). Corrosion in electronic devices and sensors to prevent corrosion. International Journal of Engineering Research and Applications, 4(2), 598-600.

Deyá, M., Romagnoli, R., \& Del Amo, B. (2004). The influence of Zinc Oxide on the anticorrosive behaviour of eco-friendly paints. Corrosion Reviews, 22(1), 1-18.

Dinh, T.-V., Choi, I.-Y., Son, Y.-S., Song, K.-Y., Sunwoo, Y., \& Kim, J.-C. (2016). Volatile Organic Compounds (VOCs) in surface coating materials: Their compositions and potential as an alternative fuel. Journal of Environmental Management, 168, 157-164.

Eklund, B. M., \& Nelson, T. P. (1995). Evaluation of VOC emission measurement methods for paint spray booths. Journal of the Air and Waste Management Association, 45(3), 196-205.

Faisal, M., \& Hasnain, S. (2006). Hazardous impact of chromium on environment and its appropriate remediation. Journal of Pharmacology and Toxicology, 1(3), 248258.

Fan, Z. T., Zhu, X., Jung, K. H., OhmanStrickland, P., Weisel, C. P., \& Lioy, P. J. (2012). Exposures to Volatile Organic Compounds (VOCs) and associated health risks of socio-economically disadvantaged 
population in a "hot spot" in Camden, New Jersey. Atmospheric Environment, 57, 7279.

Fidrusli, A., \& Mahmood, M. (2018). Ginger extract as green corrosion inhibitor of mild steel in hydrochloric acid solution. IOP Conference Series: Materials Science and Engineering. Kuala Lumpur, MY, 012087.

George, K., \& Nešic, S. (2007). Investigation of carbon dioxide corrosion of mild steel in the presence of acetic acid-Part 1: Basic mechanisms. Corrosion, 63(2), 178-186.

Haggag, E. G., Kamal, A. M., Abdelhady, M. I., El-Sayed, M. M., El-Wakil, E. A., \& Abd-El-hamed, S. S. (2011). Antioxidant and cytotoxic activity of polyphenolic compounds isolated from the leaves of Leucenia leucocephala. Pharmaceutical Biology, 49(11), 1103-1113.

Hong, S.-H., Shin, D.-C., Lee, Y.-J., Kim, S.-H., \& Lim, Y.-W. (2017). Health risk assessment of Volatile Organic Compounds in urban areas. Human and Ecological Risk Assessment, 23(6), 1454-1465.

Jafari, Y., Ghoreishi, S. M., \& ShabaniNooshabadi, M. (2016). Polyaniline/ graphene nanocomposite coatings on copper: electropolymerization, characterization, and evaluation of corrosion protection performance. Synthetic Metals, 217, 220230.

Jafari, Y., Ghoreishi, S. M., \& ShabaniNooshabadi, M. (2016). Electrochemical deposition and characterization of polyaniline-graphene nanocomposite films and its corrosion protection properties. Journal of Polymer Research, 23(5), 91.

Khanchi, A., Hebbern, C. A., Zhu, J., \& Cakmak, S. (2015). Exposure to Volatile Organic Compounds and associated health risks in Windsor, Canada. Atmospheric Environment, 120, 152-159.

Lai, C., Xie, B., Zou, L., Zheng, X., Ma, X., \& Zhu, S. (2017). Adsorption and corrosion inhibition of mild steel in hydrochloric acid solution by S-allyl-O, O'dialkyldithiophosphates. Results in Physics, 7, 3434-3443.

Marzorati, S., Verotta, L., \& Trasatti, S. (2019). Green corrosion inhibitors from natural sources and biomass wastes. Molecules, 24(1), 48 .

Mo, S., Luo, H.-Q., \& Li, N.-B. (2016). Plant extracts as "Green" corrosion inhibitors for steel in sulphuric acid. Chemical Papers, 70(9), 1131-1143.

Mohammed, R. S., El Souda, S. S., Taie, H. A., Moharam, M. E., \& Shaker, K. H. (2015). Antioxidant, antimicrobial activities of Flavonoids Glycoside from Leucaena leucocephala leaves. Journal of Applied Pharmaceutical Science, 5(6), 138-147.

Mostafaei, A., \& Nasirpouri, F. (2014). Epoxy/Polyaniline-Zno nanorods hybrid nanocomposite coatings: Synthesis, characterization and corrosion protection performance of conducting paints. Progress in Organic Coatings, 77(1), 146-159.

Novotnik, B., Zuliani, T., Ščančar, J., \& Milačič, R. (2012). The determination of $\mathrm{Cr}$ (VI) in corrosion protection coatings by speciated isotope dilution ICP-MS. Journal of Analytical Atomic Spectrometry, 27(9), 1484-1493.

Peter, A., Obot, I., \& Sharma, S. K. (2015). Use of natural gums as green corrosion inhibitors: An overview. International Journal of Industrial Chemistry, 6(3), 153164.

Ray, R. R. (2016). Adverse hematological effects of Hexavalent Chromium: An overview. Interdisciplinary Toxicology, 9(2), 55-65.

Razavi, F. S., Shabani-Nooshabadi, M., \& Behpour, M. (2018). Sol-gel synthesis, characterization and electrochemical corrosion behavior of SNC-doped $\mathrm{TiO} 2$ nano coating on copper. Journal of Molecular Liquids, 266, 99-105. 
Revie, R. W., \& Uhlig, H. H. (2008). Corrosion and corrosion control: An introduction to corrosion science and engineering. New Jersey, USA: John Wiley \& Sons.

Shabani-Nooshabadi, M., Ghoreishi, S. M., \& Behpour, M. (2011). Direct electrosynthesis of polyaniline-montmorrilonite nanocomposite coatings on aluminum alloy 3004 and their corrosion protection performance. Corrosion Science, 53(9), 3035-3042.

Shabani-Nooshabadi, M., Mollahoseiny, M., \& Jafari, Y. (2014). Electropolymerized coatings of polyaniline on copper by using the galvanostatic method and their corrosion protection performance in $\mathrm{HCl}$ medium. Surface and Interface Analysis, 46(7), 472-479.

Shabani-Nooshabadi, M., Hoseiny, F. S., \& Jafari, Y. (2015). Green approach to corrosion inhibition of copper by the extract of Calligonum comosum in strong acidic medium. Metallurgical and Materials Transactions A, 46(1), 293-299.

Shehata, O. S., Korshed, L. A., \& Attia, A. (2018). Green corrosion inhibitors, past, present, and future. In M. Aliofkhazraei (Ed.) Corrosion inhibitors, principles and recent applications. (pp. 121). London, UK: IntechOpen.

Shuai, J., Kim, S., Ryu, H., Park, J., Lee, C. K., Kim, G.-B., Ultra, V. U., \& Yang, W. (2018). Health risk assessment of Volatile Organic Compounds exposure near Daegu
Dyeing Industrial Complex in South Korea. BMC Public Health, 18(1), 528-541.

Tzaneva, B. (2013). Effect of pH on the corrosion behaviour of high nitrogen stainless steel in chloride medium. Journal of Chemical Technology \& Metallurgy, 48(4), 383-390.

Verma, C., Ebenso, E. E., Bahadur, I., \& Quraishi, M. (2018). An overview on plant extracts as environmental sustainable and green corrosion inhibitors for metals and alloys in aggressive corrosive media. Journal of Molecular Liquids, 266, 577-590.

Verma, C., Verma, D. K., Ebenso, E. E., \& Quraishi, M. A. (2018). Sulfur and Phosphorus Heteroatom-containing compounds as corrosion inhibitors: An overview. Heteroatom Chemistry, 29(4), $1-20$.

Yu, C. W., \& Kim, J. T. (2012). Long-term impact of Formaldehyde and VOC emissions from vood-based products on indoor environments; and issues with recycled products. Indoor and Built Environment, 21(1), 137-149.

Zarina, Z., Ghazali, C., \& Sam, S. (2017). Characterization analysis for leaves of Leucaena leucocephala by using Phytochemical Screening Assay. AIP Conference Proceedings. Krabi, TH, 1-8.

Zayed, M. Z., \& Samling, B. (2016). Phytochemical constituents of the leaves of Leucaena leucocephala from Malaysia. International Journal of Pharmacy and Pharmaceutical Sciences, 8(12), 174-179. 